\title{
CORRESPONDENCE
}

\section{Response to Jaime A Teixeira da Silva's article, "Suggestions for fortifying the discoverability of papers published in European Science Editing"}

\section{Tom Lang}

Associate Editor, European Science Editing; tomlangcom@aol.com

In response to Jaime A Teixeira da Silva's article, “Suggestions for fortifying the discoverability of papers published in European Science Editing": ${ }^{1}$

We are pleased the author took the time to assess the online presence of the journal. To clarify: only abstracts are available in html because the conversion costs are prohibitive. Also, the DOI appears on all html versions as a link at the top of the page, and all 11 of our articles published on the ARPHA platform are available on the Directory of Open Access Journals. The author is also correct that additional resources are needed to index articles published more than 17 years ago. The journal has no paid staff and a limited budget; retrospective fixes will just have to wait!

\section{References}

1 Teixeira de Silva JA. Suggestions for fortifying the discoverability of papers published in European Science Editing. Eur Sci Ed 2020; 46: doi: 10.3897/ ese.2020.e57377 